\title{
Experimental and numerical study on the bearing capacity of encased stone columns
}

\author{
N. Hataf*, N. Nabipour and A. Sadr
}

*Correspondence: nhataf@shirazu.ac.ir Department of Civil and Environmental Engineering, Shiraz University, Shiraz, Iran

\begin{abstract}
Stone columns have attracted considerable attention as a ground improvement techniques recently. Performance of stone columns, however, depends on confining pressure offered by the surrounding soils. In the case of very soft soils, the lateral confining pressure may be insufficient and this may lead to column bulging failure. Encapsulating the individual stone column enhances the lateral resistance against bulging by additional confining pressure. In this study, the influences of the length of encasement and type of aggregate materials on the bearing capacity of a single stone column in both dry sand and clay bed were investigated. The results indicated a clear improvement by encasing the half-length of the column. The numerical study also showed the effect of reinforcement stiffness reduces with increase in the cohesion of the clay. Parametric study showed that the effect of encasement stiffness is insignificant for clay bed with high values of cohesion.
\end{abstract}

Keywords: Bearing capacity, Stone column, Encasement length

\section{Introduction}

Civil engineering projects are often encountered with serious problems in soft soils. There are many methods of soil improvement, among them, soil reinforcing with stone columns is more usual and also environmental friendly [2, 13, 14, 16, 23]. For very soft soils with undrained cohesion, ${ }_{\mathrm{Cu}}$, lower than $15 \mathrm{kPa}$, encapsulating the stone column by geosynthetics as an alternative method is used [8]. With encasing the stone columns, confining pressure around columns increases leading to increasing in bearing capacity and reduction in settlement $[1,5,18,21]$. Murugesan and Rajagopal [21] suggested the following relationships to estimate the ultimate bearing capacity of the single encased stone column in clay:

$$
q_{u l t, c}=\left(\sigma_{r, 0}+4 C_{u}+\sigma_{r, g}\right) K_{p}
$$

In which in this article are included in the article's Creative Commons licence, unless indicated otherwise in a credit line to the material. If material is not included in the article's Creative Commons licence and your intended use is not permitted by statutory regulation or exceeds the permitted use, you will need to obtain permission directly from the copyright holder. To view a copy of this licence, visit http://creativeco mmons.org/licenses/by/4.0/. 
$\sigma_{\mathrm{r} 0}=$ lateral soil stress induced by the overburden stress at the middle point of the column bulging length (i.e., $2 \mathrm{~d}, \mathrm{~d}$ is the column diameter). $\sigma_{\mathrm{r}, \mathrm{g}}=$ additional confining stress by geosynthetic encasement. $K_{p}=$ coefficient of passive earth pressure of the column

The additional confining stress can be calculated by considering the hoop tensile force in the geosynthetic encasement as follows:

$$
\sigma_{r, g}=\frac{2 T_{g}}{d_{c}}
$$

where $T_{g}$ and $d_{c}$ are the hoop tensile force of the geosynthetic and column diameter respectively. The hoop tensile force may be controlled by the geosynthetic elongation at failure (typically at $5 \%$ ).

Having conducted a series of triaxial test, Miranda and Da Costa [18] showed that with the increase in confining pressure $\left(\sigma_{3}\right)$ effect of encasement reduces. Also, they showed the influence of the encasement with lower mobilized friction angles in the encased samples compared to that for the non-encased ones. With respect to greater stiffness of geomesh and geogrids than geotextiles, in recent years, many investigations have been conducted on stone columns encased with geogrids [7, 11, 22. Yoo and Lee [22] performed full-scale tests and showed that the effect of encasement reduces with depth. The behavior of floating stone columns encased with geogrid was investigated by Dash and Bora [7]. They indicated that floating stone columns may show quite different behavior with respect to end-bearing ones. Many numerical investigations have been done to study the affecting parameters on encased stone columns $[9,19]$. Keykhosropur et al. [15] numerically analyzed the behavior of encased stone column beneath the embankment and showed that encasing only the outer columns of the stone column group is sufficient in providing an optimal design. Although the effect of encasement on increasing the efficiency of stone columns are observed and reported in literature the effect of encasement length to column length ratio on bearing capacity of stone columns and aggregate properties have not been studied as much. In this research, the effect of soil improving using stone column encased with geomesh with different encasement length to column length ratios and aggregate properties are investigated in the laboratory. Numerical study using a finite element computer code, PLAXIS-2D has been also conducted to investigate the influence of soil cohesion, stiffness and length of reinforcement on load bearing capacity of stone columns.

\section{Materials and methods}

The effects of aggregate properties and length of encasement on the behavior of stone columns were studied by conducting a series of laboratory testing on physical models. The stone columns were embedded in both sand and clay.

\section{Material properties}

Two types of soil were used; a clay soil as a cohesive bed and a sandy soil as a granular bed. Physical properties of the soils obtained through laboratory tests, are listed in Table 1. Grain size distribution curves for the soils used are illustrated in Fig. 1. Direct shear tests were performed according to the standard ASTM D 3080 to determine the internal friction angle and cohesion of soils used. The unit weights for sand 
Table 1 Physical properties of the soils tested

\begin{tabular}{lrr}
\hline Parameter & Clay & Sand \\
\hline Friction angle & 26.0 & 35.0 \\
Cohesion $\left(\mathrm{kN} / \mathrm{m}^{2}\right)$ & 5.0 & 0.0 \\
Unit weight $\left(\mathrm{kN} / \mathrm{m}^{3}\right)$ & 15.0 & 16.0 \\
Liquid limit $(\%)$ & 44.5 & - \\
Plasticity index (\%) & 20.0 & - \\
\hline
\end{tabular}

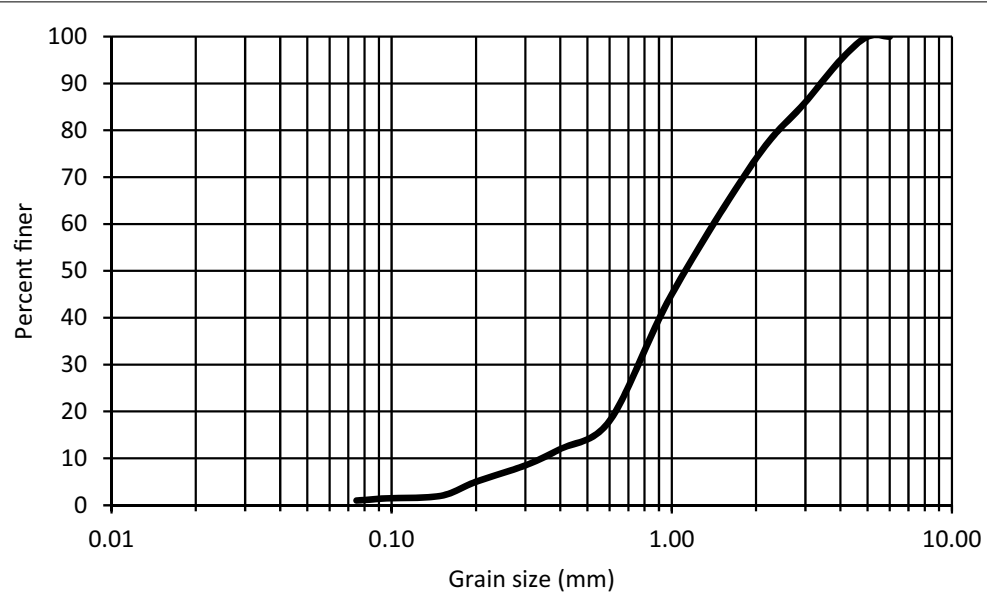

a Sand grain size distribution curve

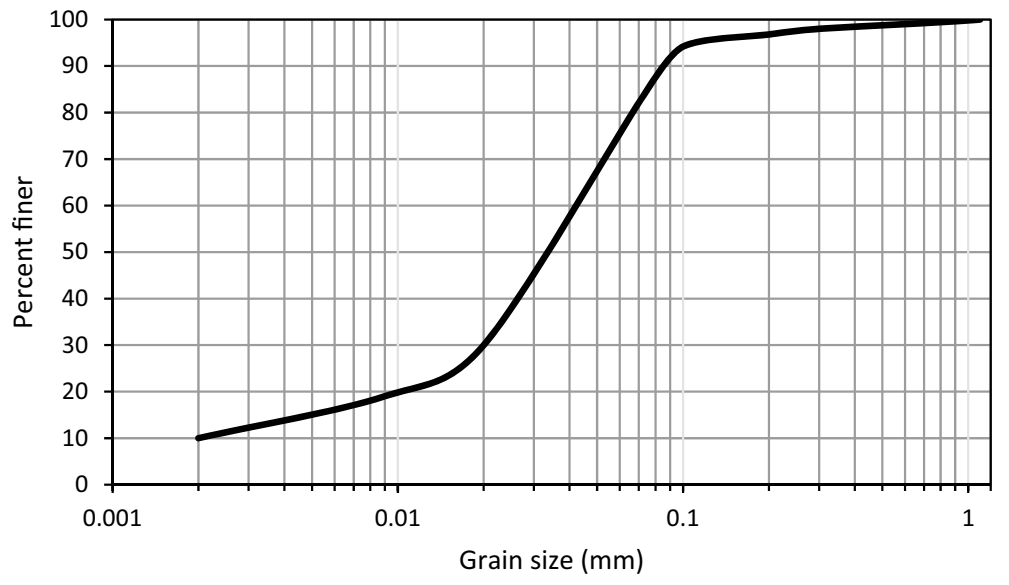

b Clay grain size distribution curve

Fig. 1 Grain size distribution curves for soils used

and clay were 16 and $15 \mathrm{kN} / \mathrm{m}^{3}$ respectively. Three types of aggregates were used to form stone columns $\left(R_{1}, R_{2}\right.$ and $\left.R_{3}\right)$, Fig. 2 . The internal friction angles for $R_{1}, R_{2}$ and $R_{3}$ were $38^{\circ}, 41^{\circ}$ and $44^{\circ}$, respectively. It is important to note that according to Fig. $2, R_{1}$ and $R_{3}$ have minimum and maximum size of aggregates. The unit weights of 


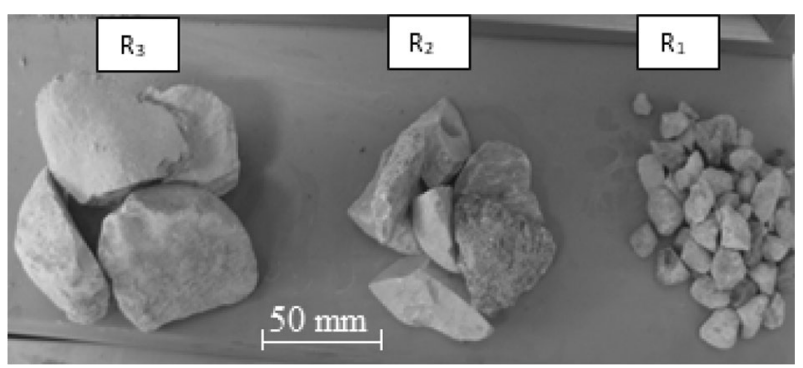

Fig. 2 Aggregate materials used: fine aggregate $R_{1}$, medium aggregate $R_{2}$, coarse aggregate $R_{3}$

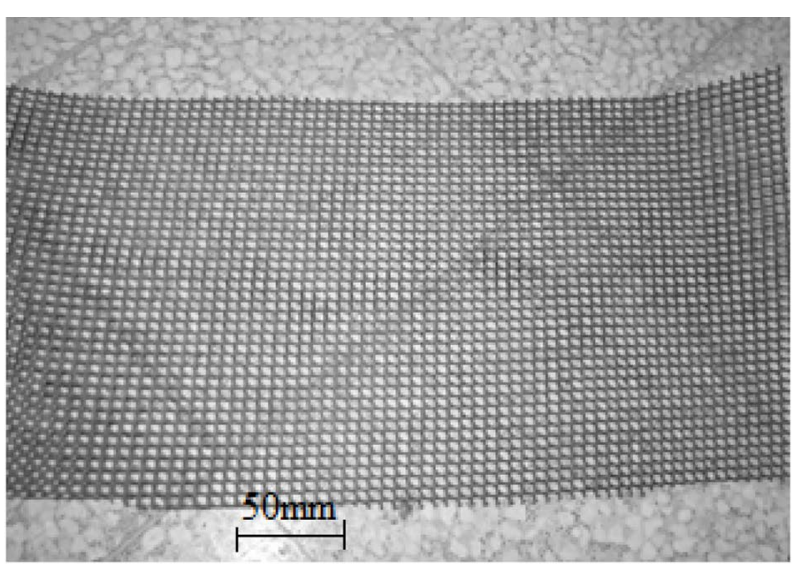

(a) Geomesh before test

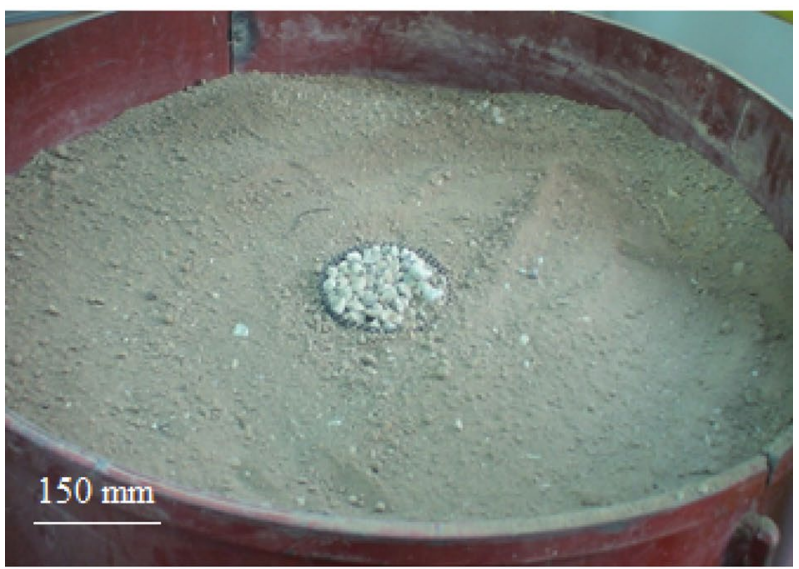

(b) Geomesh wrapped around stone column ready for the test

Fig. 3 Geomesh used for encasement

aggregates were 18,20 and $21.5 \mathrm{kN} / \mathrm{m}^{3}$, respectively. Grading of all aggregate materials is almost uniform.

To encase the stone column, a geomesh with tensile stiffness equal to $8 \mathrm{kN} / \mathrm{m}$ was used. Large apertures of selected geomesh allow considerable contact between 
aggregates inside the column and surrounding soils (Fig. 3), and meanwhile, the aggregates cannot move out of the casing.

\section{Preparation of test model}

A cylindrical test tank $1 \mathrm{~m}$ in diameter and $1 \mathrm{~m}$ in height was used to accommodate the soil and stone column. Previous researches revealed that the influence zone of stone columns is 2 to 4 times of radius of column [6], as a result, the $50 \mathrm{~cm}$ radius of test tank doesn't affect the results of experiment for column diameter of $15 \mathrm{~cm}$. To prepare a soil bed, at first, two layers of $10 \mathrm{~cm}$ thickness was placed and compacted with a $5 \mathrm{~kg}$ weight falling freely from a height of $40 \mathrm{~cm} 20$ times. A number of containers with specified volume were put inside each layer at different locations to check the uniformity of compaction prior to soil pouring and tamping. After the experiment, the samples were weighed and the soil density was measured. The test was repeated if there were layers, not compacted appropriately. To model stone column a casing pipe with a diameter slightly greater than the required diameter (i.e. $15 \mathrm{~cm}$ ) was used. The casing pipe was installed at the center of the tank. To encapsulate stone column, the geogrid layer was wrapped around the casing pipe and was overlapped equal to the inner perimeter of the pipe. Gniel and Bouazza [12] showed this amount of overlapping is adequate. Next, the tank was filled with soil to reach a desirable level. Casing pipe was filled with aggregate materials in layers of $10 \mathrm{~cm}$ thickness. After placing each layer, the casing was raised and materials were gently compacted with a steel rod. Three strain gauges oriented at $120^{\circ}$ to each other were located on the plate loading to measure settlements. The stone columns loaded statically to failure or pre-specified settlement. Figure 4 illustrates the stone column installed and ready to be loaded.

\section{Test program and controlling factors}

The first goal of this study was to find out in which kind of soil, stone column encasement is more effective, so the first controlling factor was the types of soil surrounding the stone column. For this part two series of experiments were conducted using two kinds of soil, clay and sand. The other main concern of this research, was the length of encasement, as it consumes a major part of budgets in these projects. Encasement

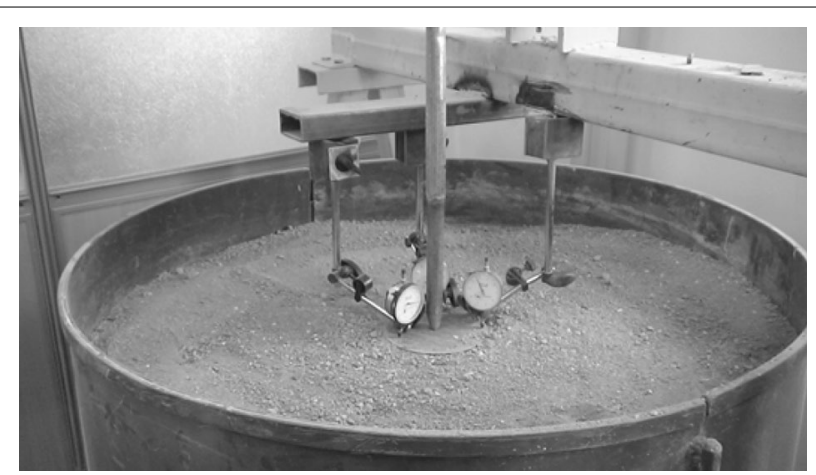

Fig. 4 Loading and measurement systems 
Table 2 The test program conducted on clay and sand soil bed

\begin{tabular}{llllllllll}
\hline Test ID on clay & C-R3-No & C-R3-H & C-R3-F & C-R2-No & C-R2-H & C-R2-F & C-R1-No & C-R1-H & C-R1-F \\
Test ID on sand & S-R3-No & S-R3-H & S-R3-F & S-R2-No & S-R2-H & S-R2-F & S-R1-No & S-R1-H & S-R1-F \\
\hline
\end{tabular}

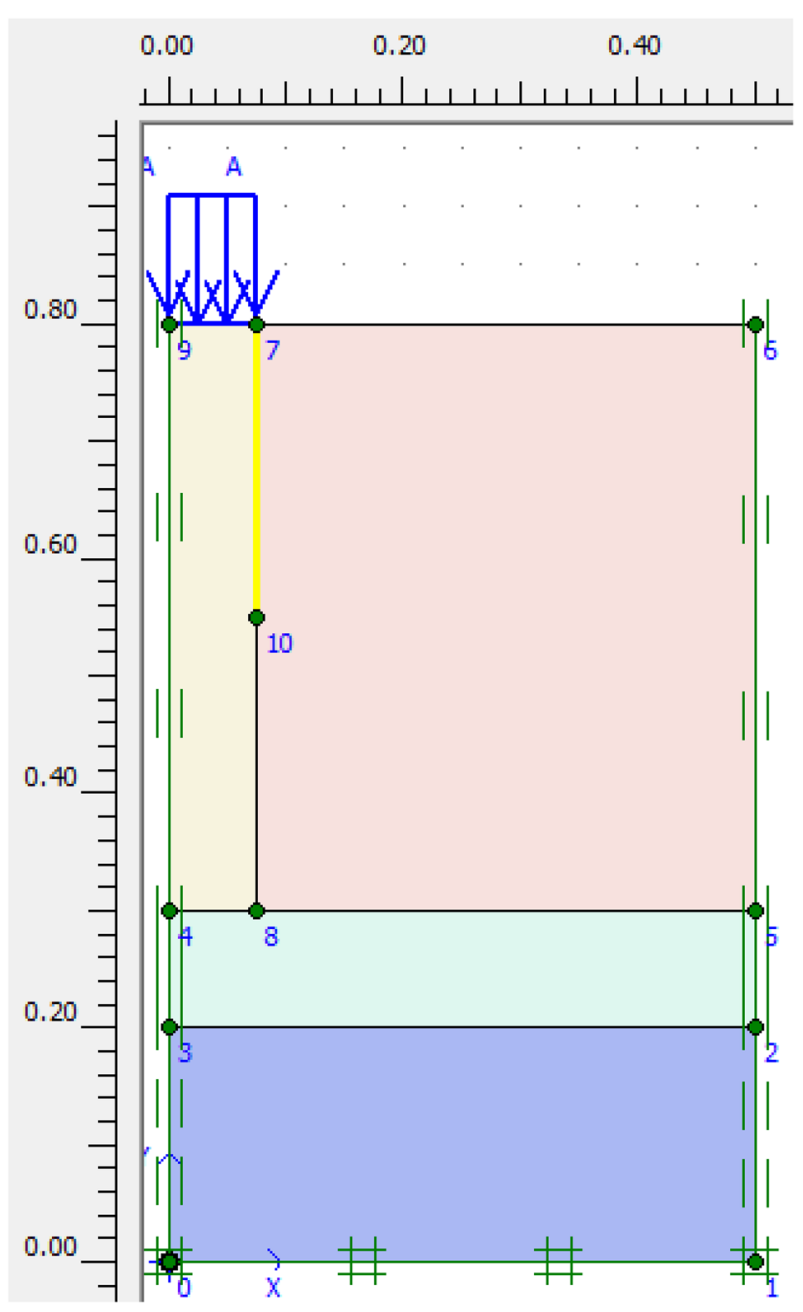

Fig. 5 Numerical modeling

was carried out in three conditions of none, half and full length encasement. The last variable, the size of aggregates was assessed using three aggregate sizes.

Table 2 illustrates the testing program conducted in this study. Letters F, H, C, S, $R_{i}$ and $\mathrm{NO}$ in this table, represent the full-length, half-length encasement, type of soil bed (i.e. $\mathrm{C}$ for clay or $\mathrm{S}$ for sand), aggregate types and no reinforcement, respectively. 
Table 3 Clay properties for numerical modeling

\begin{tabular}{lc}
\hline Parameter & Value \\
\hline Friction angle & 26.0 \\
Cohesion $\left(\mathrm{kN} / \mathrm{m}^{2}\right)$ & 5.0 \\
Unit weight $\left(\mathrm{kN} / \mathrm{m}^{3}\right)$ & 15.0 \\
Poisson's ratio & 0.35 \\
Modulus of elasticity $\left(\mathrm{kN} / \mathrm{m}^{2}\right)$ & 7000
\end{tabular}

Table 4 Sand properties for numerical modeling

\begin{tabular}{llll}
\hline Parameter & $\mathbf{R}_{\mathbf{1}}$ & $\mathbf{R}_{\mathbf{2}}$ & $\mathbf{R}_{\mathbf{3}}$ \\
\hline Friction angle & 38 & 41 & 44 \\
Cohesion $\left(\mathrm{kN} / \mathrm{m}^{2}\right)$ & 1.0 & 1.0 & 1.0 \\
Unit weight $\left(\mathrm{kN} / \mathrm{m}^{3}\right)$ & 18.0 & 20.0 & 21.5 \\
Poisson's ratio & 0.25 & 0.2 & 0.15 \\
Modulus of elasticity $\left(\mathrm{kN} / \mathrm{m}^{2}\right)$ & 70,000 & 90,000 & 120,000
\end{tabular}

\section{Numerical analysis}

To investigate different parameters effect on the behavior of encased stone columns, numerical analysis was conducted using the Plaxis nonlinear elastoplastic finite-element technique, Fig. 5 . Many researchers have reported acceptable results using 2-D analysis $[6,10]$. In this study, the axisymmetric 2-D analysis was used. At first, the results of numerical modeling were compared with the test results to ensure the validity of the numerical simulation. The Mohr-Coulomb failure criterion was assumed to govern the failure stage of the clay and stone column material. Clay bed and aggregate material properties that were applied to the numerical models are listed in Tables 3 and 4. All parameters were measured according to ASTM standard. However, the values of elastic modulus for clay, sand and aggregates were initially selected from the ranges given in literature [6] and back analysis of experimental test results.

A linear-elastic behavior for geosynthetic material was assumed. The tensile stiffness of encasement, measured according to ASTM D4595 standard, was $8 \mathrm{kN} / \mathrm{m}$ [4]. In the finite element discretization, 15-noded triangular elements were used. All analyses were performed by applying loading increments.

The assumed boundary conditions are as presented in Fig. 5, which are roller vertical conditions for lateral boundaries and the bottom boundary is fixed.

All the model dimensions as can be seen in Fig. 5 are considered exactly the same as experimental setup which means, the right boundary is $50 \mathrm{~cm}$ from axis of symmetric, the depth of soil layers are $20 \mathrm{~cm}, 10 \mathrm{~cm}$ and $50 \mathrm{~cm}$ respectively from bottom to top with the same specifications as the soil used in experimental modelling. Failure load was defined as a maximum compression load applied or the load at the settlement corresponding to $10 \%$ of column diameter. 


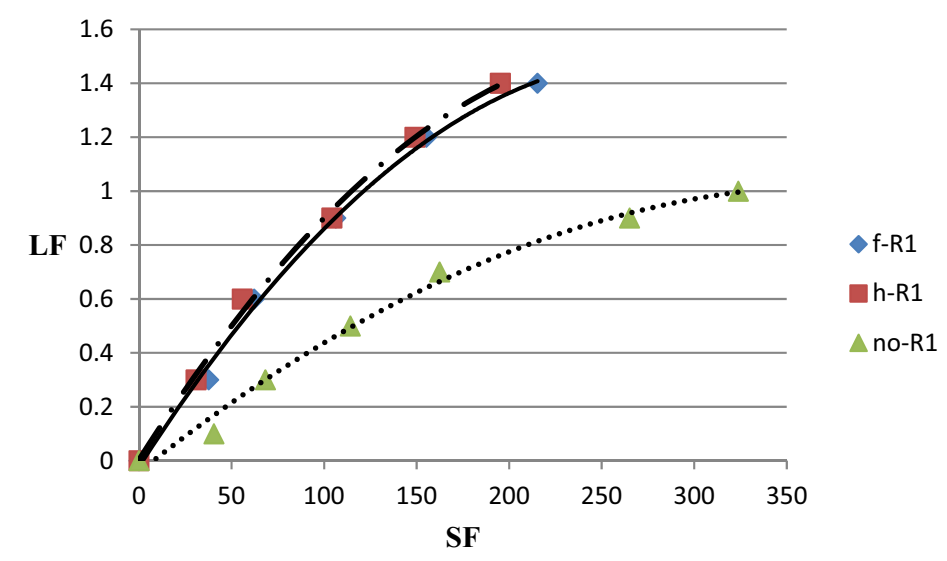

a The settlements of stone columns with fine aggregate material in clay bed

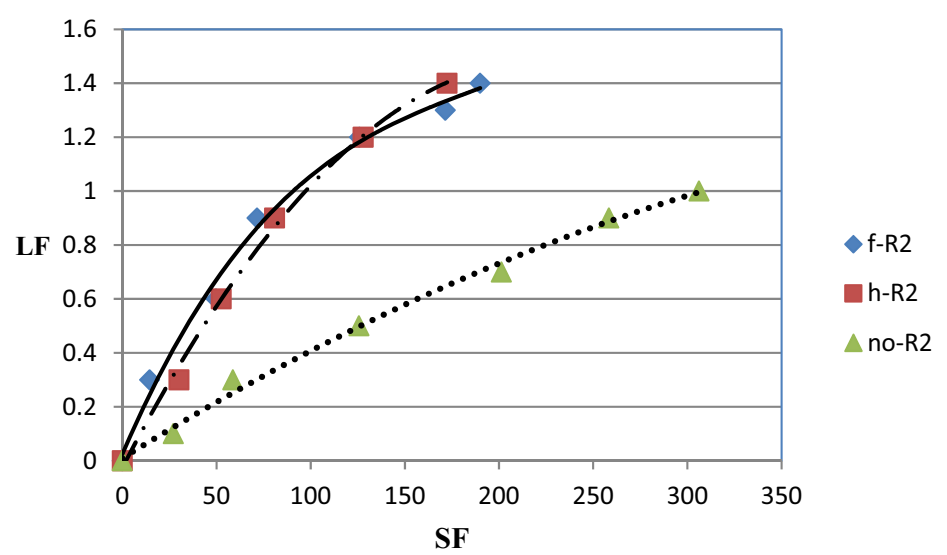

b The settlements of stone columns with medium aggregate material in clay bed

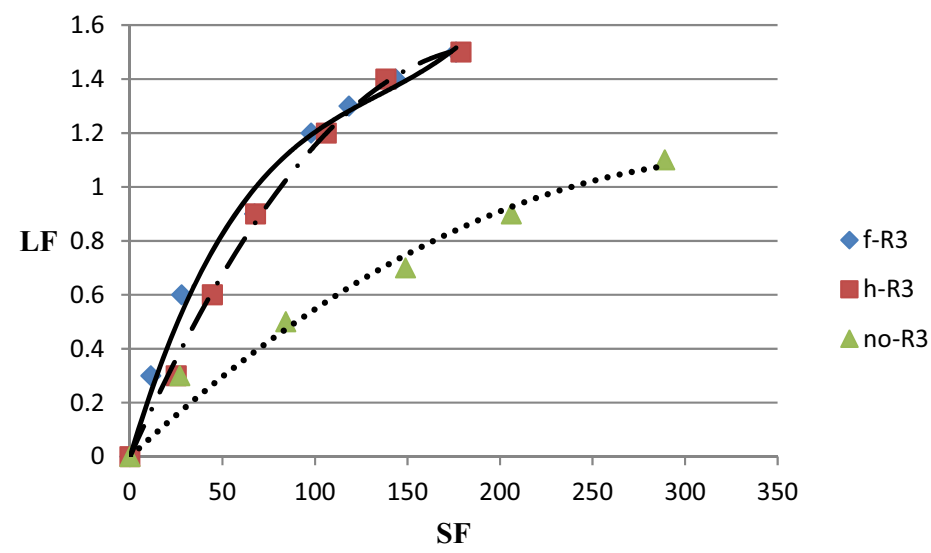

C The settlements of stone columns with aggregate material in clay bed

Fig. 6 Test results in clay bed for different lengths of encasement and aggregate materials

\section{Results and discussion}

\section{Experimental results}

Figure $6 \mathrm{a}-\mathrm{c}$ show the results of compression tests on non-encased and encased stone 


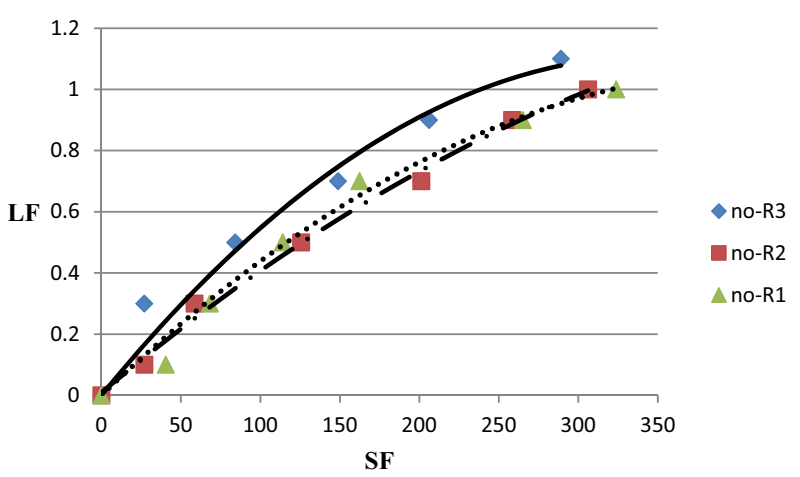

a The settlements of non-reinforced stone columns in clay bed with 3 aggregate sizes

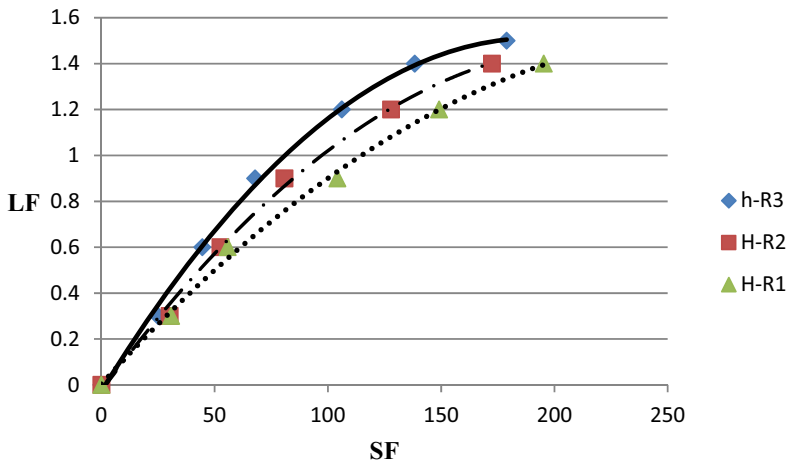

b The settlements of half-reinforced stone columns with 3 aggregate sizes in clay bed

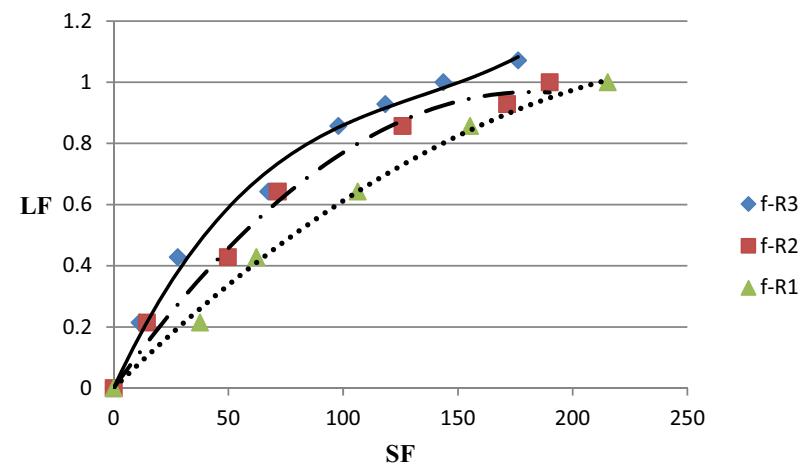

C The settlements of full-reinforced stone columns with 3 aggregate sizes in clay bed

Fig. 7 Test results in clay bed for 3 aggregates sizes with different encasement lengths

columns with full or half-length of encasing and for different types of aggregate materials in clay bed. To illustrate the influence of encasement, load factor (LF) is defined as the ratio of applied loads on the stone columns, F, to the maximum applied load on the non-encased stone column, $F_{\max (n o)}$, with similar aggregate. For example the maximum load carried by the none rainforced stone column with fine aggregates in granular soil was $4958.80 \mathrm{~N}$ whereas the load bearing capacity for the half-length stone column with the same material in the same soil was $6987.40 \mathrm{~N}$. This gives the value of load factor equal to 1.41. The abscissa in all these figures is a non-dimensional parameter (SF) defined as the ratio of column settlement, $U$, to the radius 


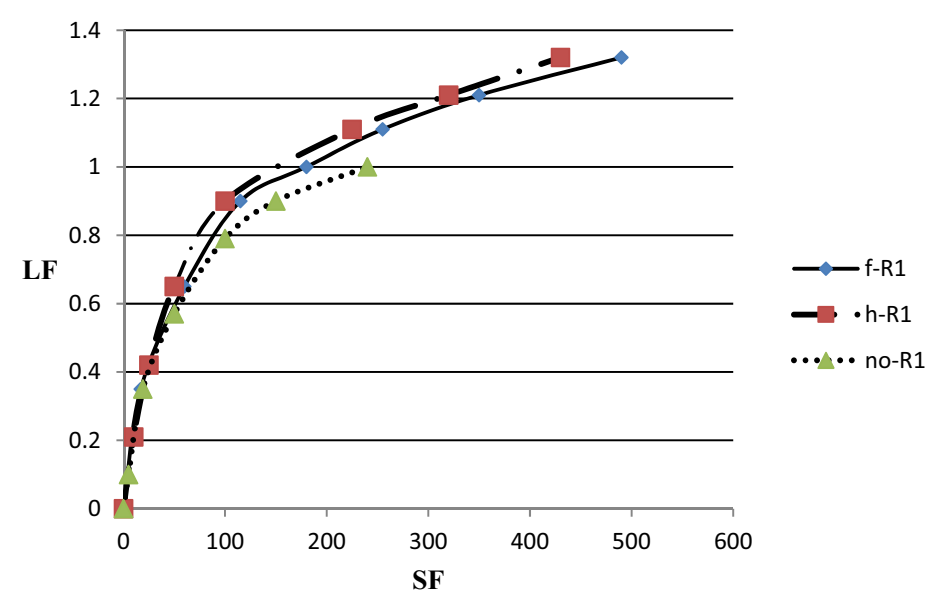

a The settlements of stone columns with fine aggregate material in sand bed

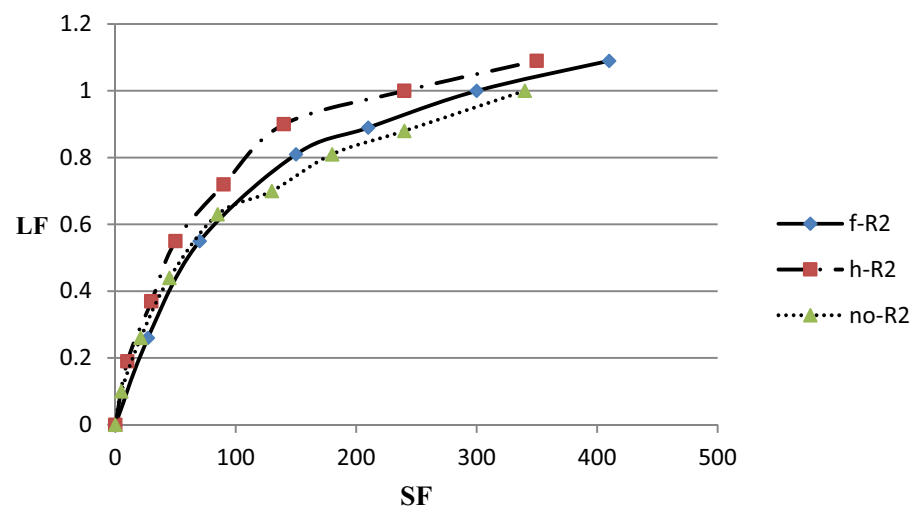

b The settlements of stone columns with medium aggregate material in sand bed

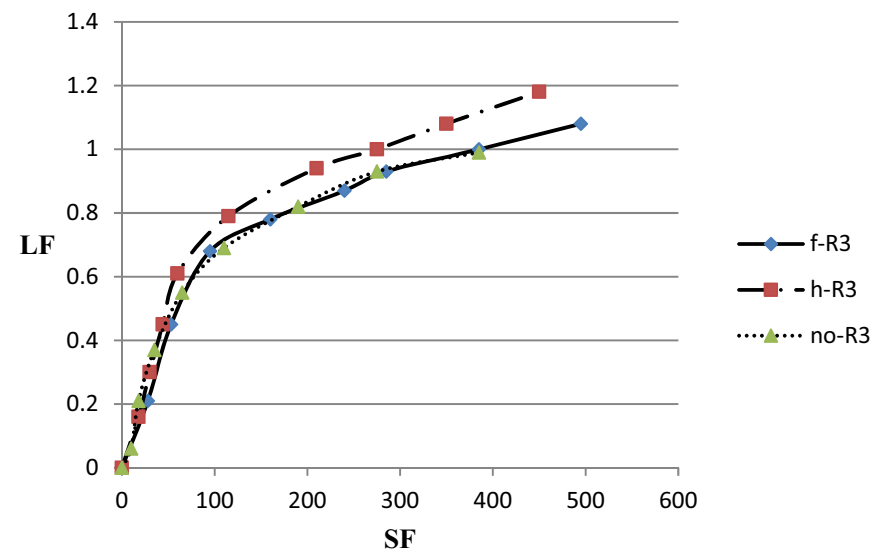

c The settlements of stone columns with coarse aggregate material in sand bed

Fig. 8 Test results in sand bed for different lengths of encasement and aggregate materials

of the column (i.e. $R=7.5 \mathrm{~cm}$ ). In these figures $\mathrm{f}-\mathrm{Ri}$, $\mathrm{h}-\mathrm{Ri}$ and no-Ri stand for fulllength, half-length and no casing stone column, respectively. Figure $6 \mathrm{a}-\mathrm{c}$ depict that the maximum value of load factor is equal to 1.4 which means encasing the stone 


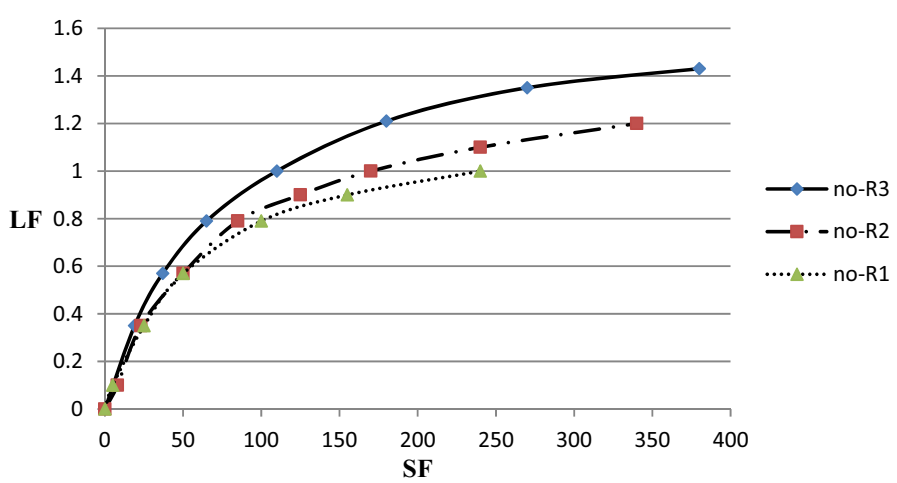

$\mathbf{a}$ The settlements of non-reinforced stone columns with 3 aggregate sizes in sand bed

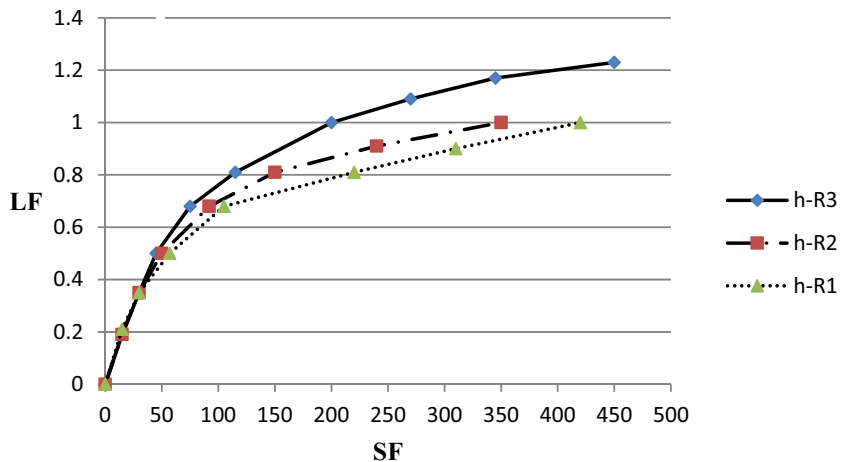

b The settlements of non-reinforced stone columns with 3 aggregate sizes in sand bed

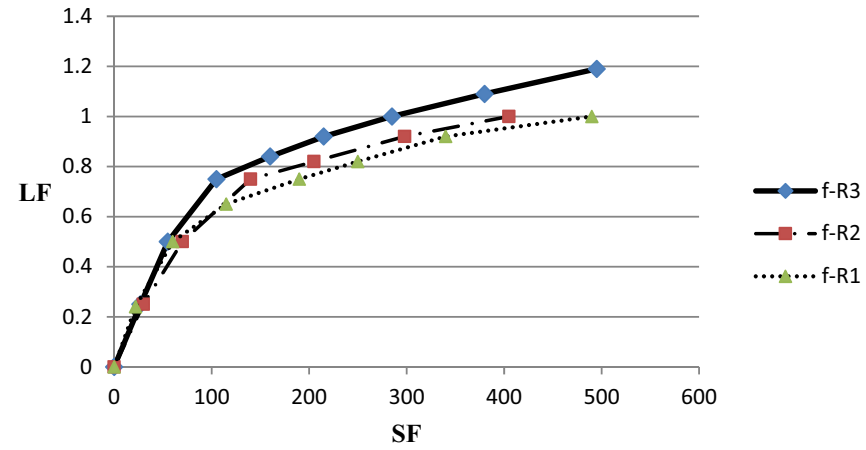

C The settlements of non-reinforced stone columns with 3 aggregate sizes in sand bed

Fig. 9 Test results in sand bed for different aggregate materials and length of encasement

columns increases the bearing capacity of the stone column as much as $40 \%$. This is in agreement with findings of Debnath and Dey, $[8,17]$ who reported that stone-column encasement increases the efficiency of stone columns significantly. It worth mentioning that although small scale models have been used in this research, the same behavior has been observed from test results on the full-scale stone columns as reported by Yoo and Lee [22]. For aggregate material type $R_{1}$ use of half-length of encasement leads to better results than full-length one (Fig. 6a). Although for other material $\left(R_{2}\right.$ and $R_{3}$ ), Fig. $6 b$, c, full-length of encasement shows better results, this improvement 
is not significant, hence it seems for all aggregates use of half-length of encasement is preferable technically and economically. In addition, the effect of encasing is evident on reducing settlement up to $60 \%$ of that for non-encased one (Fig. 6).

The effect of aggregate material for each type of stone columns located in clay bed (non-encased, half or full-encased) is illustrated in Fig. 7a-c. As it can be seen using coarser materials results in stiffer behavior.

Influence of encasing in sand bed are shown in Fig. 8a-c. As it can be observed the effect of length of encasement reduces in granular soil. The main reason is attributed to the larger confining pressure for sand. In addition, encasing of stone columns including aggregate $\mathrm{R}_{1}$ (smaller size) shows higher performance. Also reinforcing the half-length of the column including aggregate $R_{1}$ is more appropriate than full-length encasement (similar to clay bed). Gniel and Bouazza [11] showed a decrease in the radial strain of encased stone column leads to a decrease in tensile stress induced in geosynthetic and in the other words confining pressure reduces. Using coarser materials $\left(R_{2}\right.$ and $\left.R_{3}\right)$ reduces radial strain, so the efficiency of encasement also reduces. Figures 8 also clearly show at small settlements the effect of encasement is insignificant. The load-settlement behavior of stone columns for all cases at initial steps of loading is identical, probably because of small elongation of encasement and an accordingly insignificant amount of additional confining pressure.

Figure $9 \mathrm{a}-\mathrm{c}$ depict the influence of aggregate materials and length of encasement in the sand bed. The effect of using coarser materials for the non-encased stone column (Fig. 9a) is more evident than encased one. For the non-encased stone column using coarser material increases bearing capacity up to 1.4 times relative to the material, $R_{1}$ can be observed, whereas for half-length and full-length encasement this improvement is about 1.25 and 1.18 , respectively.

\section{Numerical analysis results}

\section{Stress distribution along the column length}

Figure 10a, b demonstrate the typical stress distributions for full-length and half-length encased stone column obtained using the numerical simulation of encased stone columns. As it can be seen from these figures, the maximum values of stresses are located in the upper half length of the column. The stresses reduce with depth. The same behavior has been seen for other analysis.

\section{Comparison of experimental and numerical results}

Figure 11a shows the variation of tensile stress in encasement obtained from numerical analysis and Fig. 11b shows the observed deformation of encasement in model testing. The deformation pattern of the geomesh is in good agreement with the manner of the variation of tensile stresses along the length of the encasement.

Table 5 and Fig. 12 show the comparison between the numerical and experimental results for half-length encased stone column in the sand bed. This figure ensures numerical prediction is in a good agreement with experimental measurements. This is in agreement with findings reported by Murugesan and Rajagopal [20] who numerically studied the behavior of encased stone columns. 


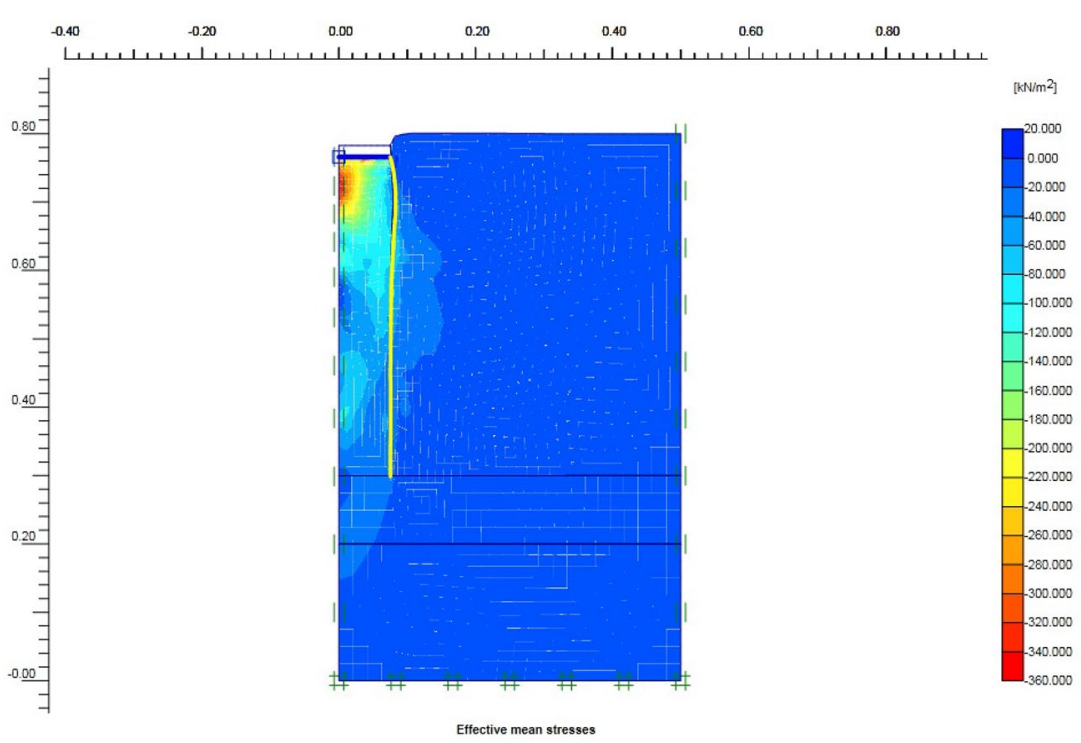

a Effective mean stress distribution for full-length encased stone column

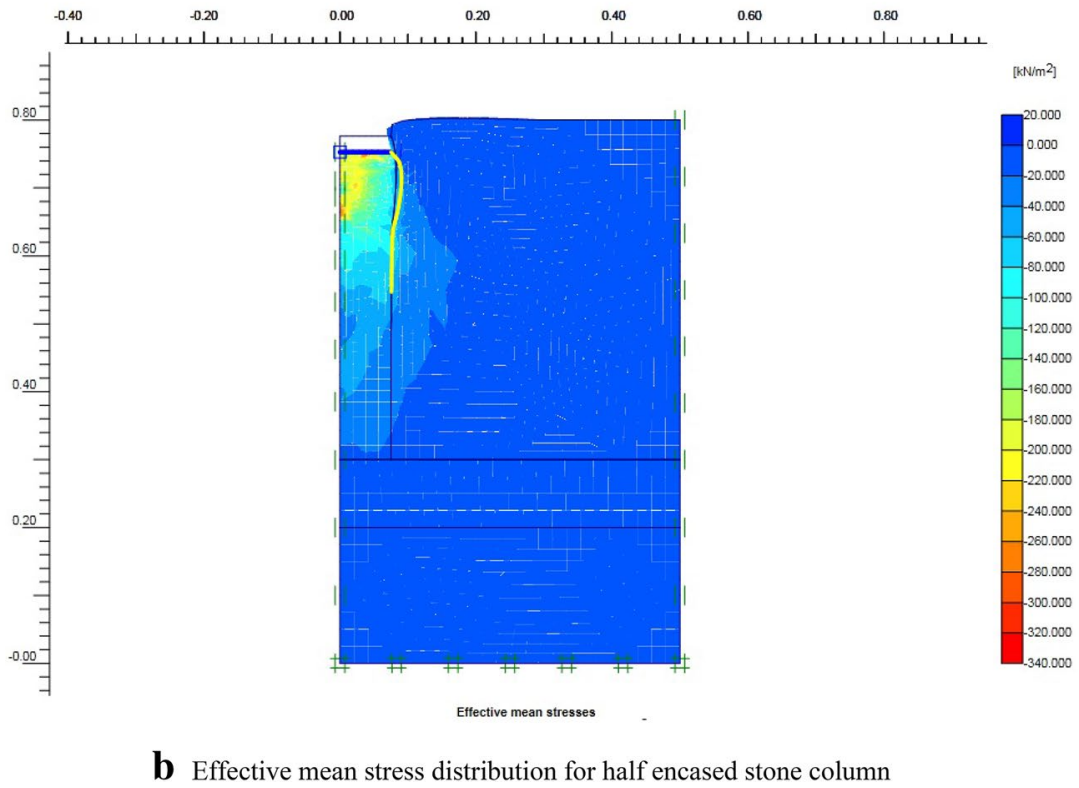

Fig. 10 Typical stress distributions for full-length and half-length encased stone column

\section{Parametric study}

After validation of numerical simulations results, parametric investigations were conducted. Figure $13 \mathrm{a}-\mathrm{d}$ show the results of the numerical analysis for clay bed with different cohesion and different stiffness of encasement material. The length of encasement was half of the column length. It is observed in Fig. 13 that the influence of the increase in load bearing capacity due to the increase in the stiffness of encasement (i.e. EA) is insignificant for high values of cohesion. This is due to the fact that the increase in cohesion leads to reduce of radial strains of stone columns which in turn pales the effect of the encasement. For high values of cohesion, therefore, the encasing of stone columns is not needed. 


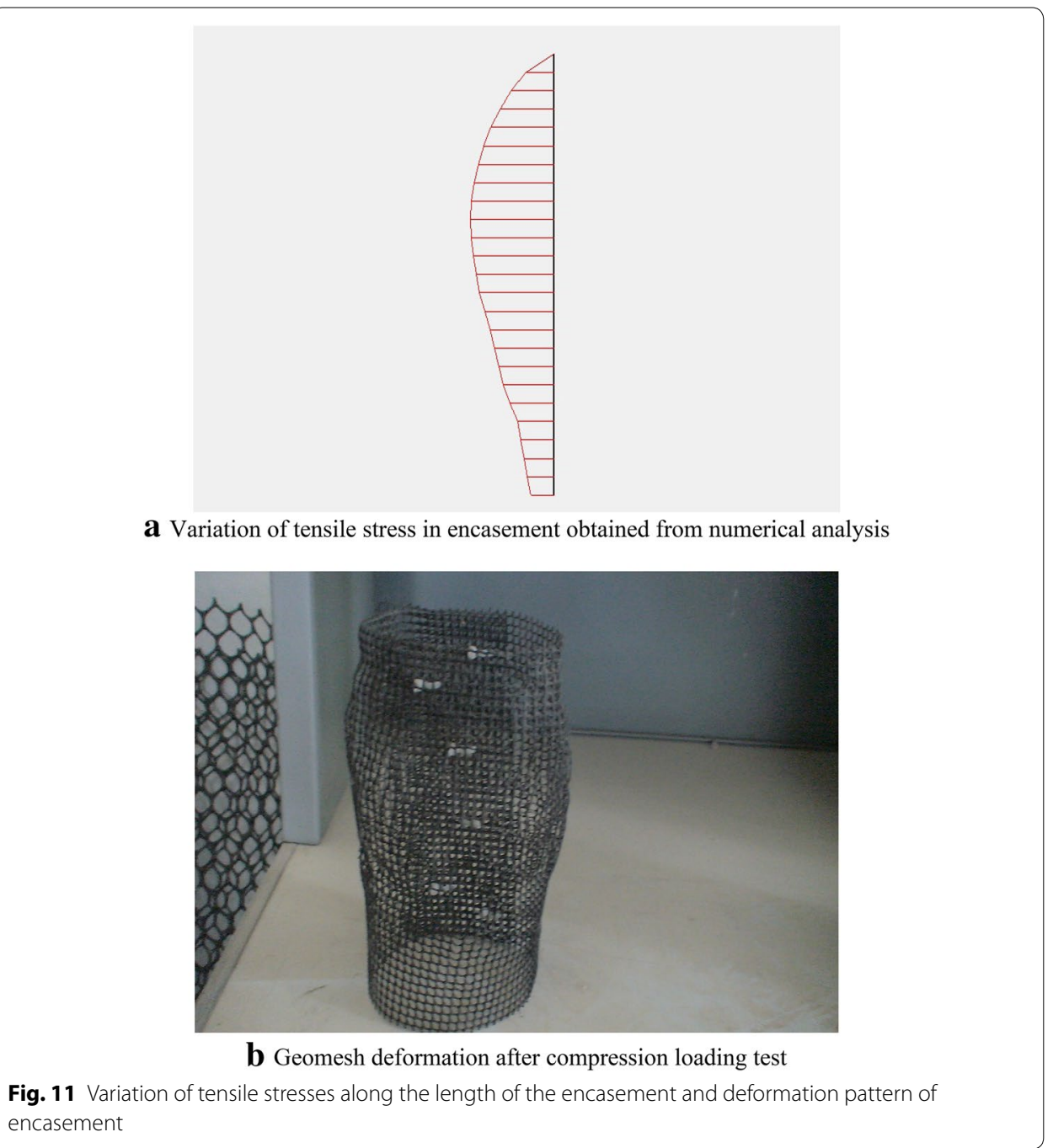

Table 5 The difference between numerical and experimental settlement for a half-length encased stone column in a sandy soil

\begin{tabular}{lccc}
\hline Force applied & \multicolumn{2}{c}{ Settlement $(\mathbf{m m})$} & Error \\
\cline { 2 - 3 } & Numerical & Experimental & \\
\hline 0.00 & 0.00 & 0.00 & 0.00 \\
20.00 & 0.52 & 0.90 & 0.42 \\
40.00 & 1.49 & 2.34 & 0.36 \\
60.00 & 3.09 & 4.31 & 0.28 \\
80.00 & 6.85 & 7.97 & 0.14 \\
100.00 & 15.02 & 16.47 & 0.09 \\
110.00 & 24.76 & 23.35 & 0.06 \\
120.00 & 33.63 & 31.51 & 0.07 \\
\hline
\end{tabular}




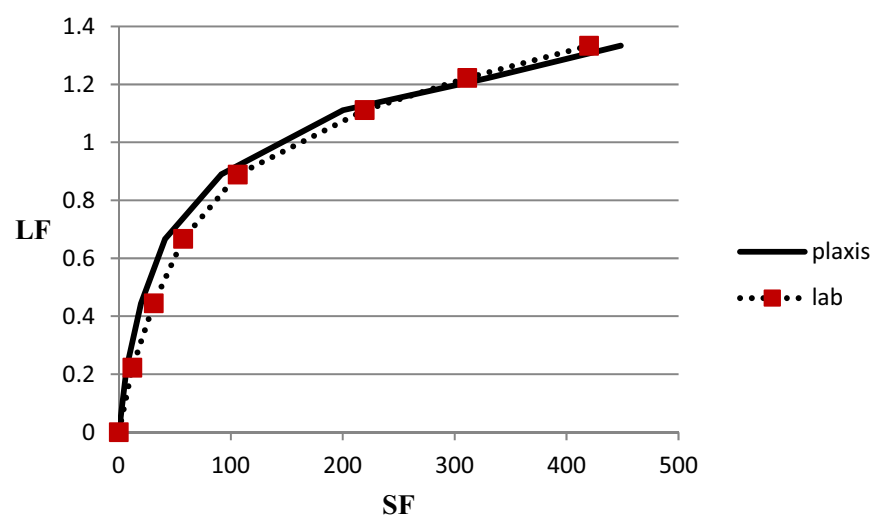

a For aggregate $\mathrm{R} 1$

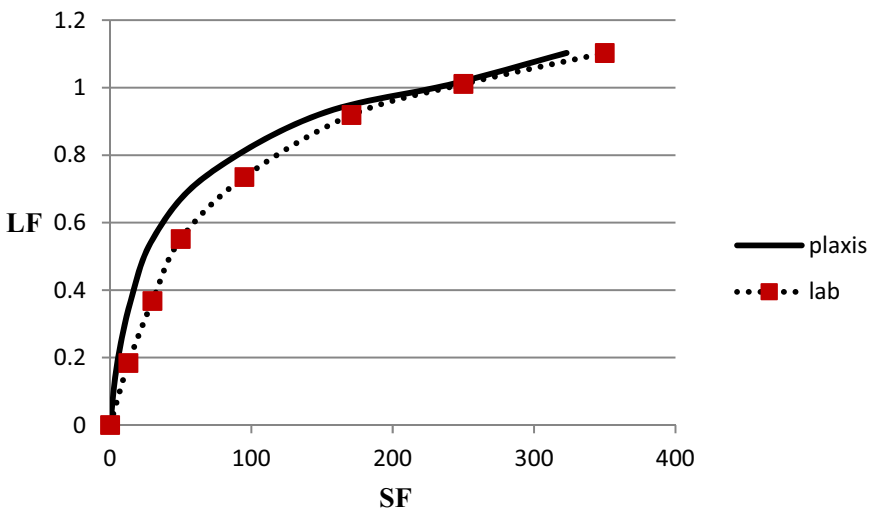

b For aggregate $\mathrm{R}_{2}$

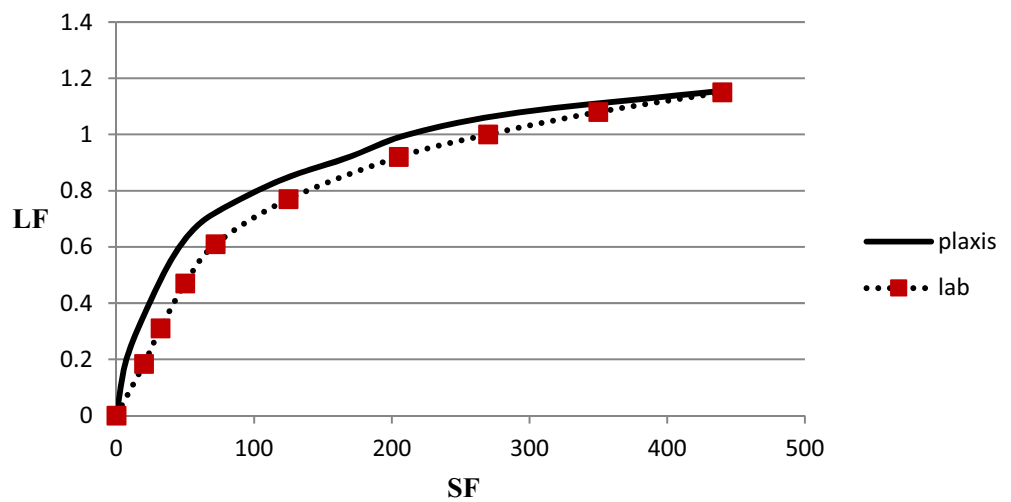

c For aggregate R3

Fig. 12 Comparison of numerical and experimental results for half-length encased stone column in sand bed

Figure 14 depicts the results of numerical simulation of encased stone columns in clay soil bed with different lengths of encasement and aggregates. It is revealed that regarding the increase in bearing capacity and decrease in the corresponding settlement, the half-length encasement is economically and technically sufficient for soil improvement. 


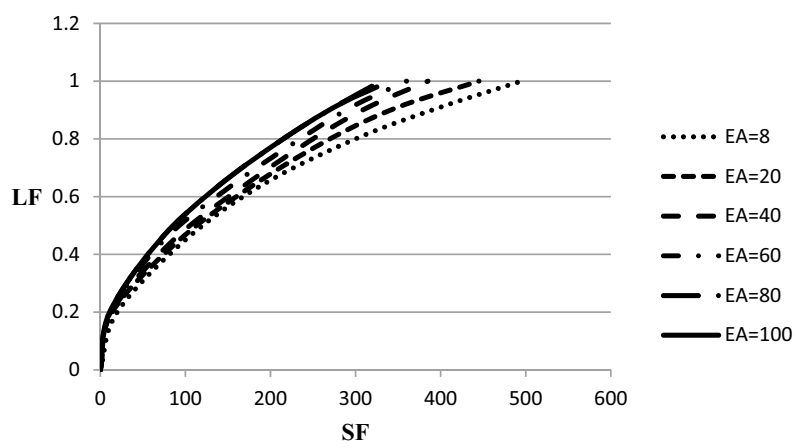

a $\mathrm{C}=5 \mathrm{kPa}$

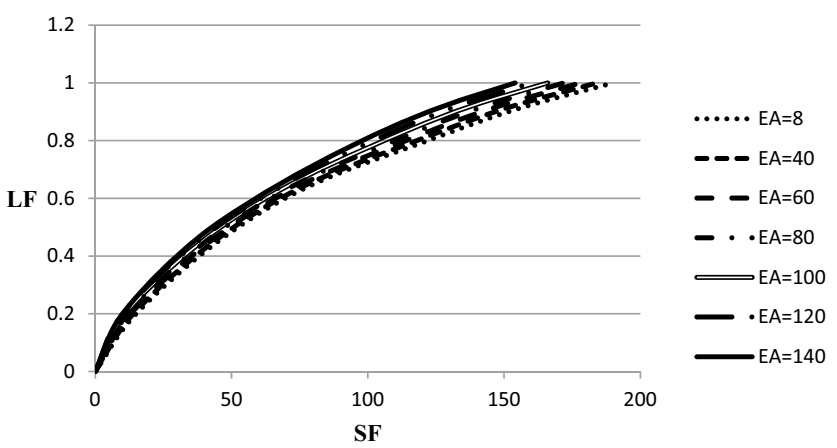

b $\mathrm{C}=15 \mathrm{kPa}$

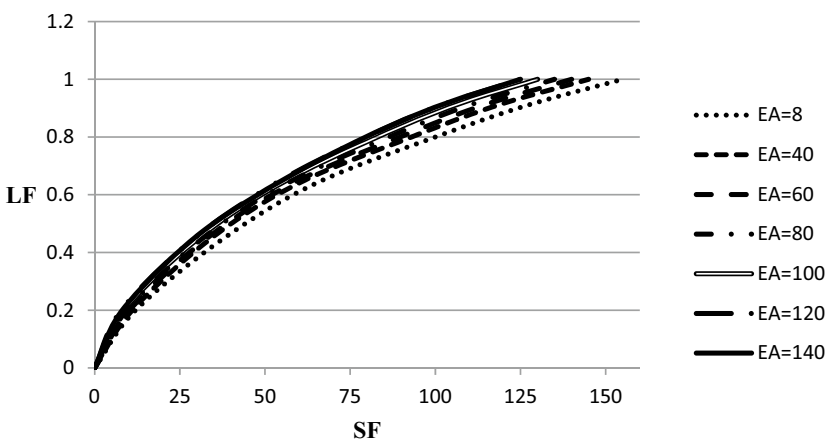

c $\mathrm{C}=20 \mathrm{kPa}$

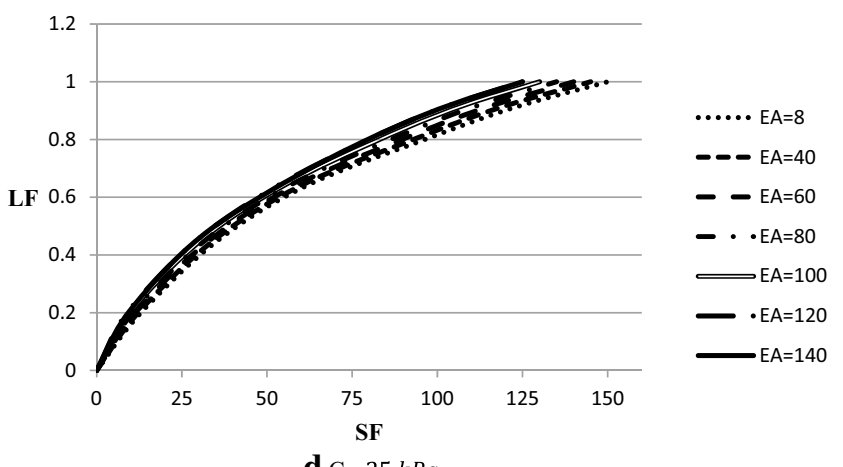

d $\mathrm{C}=25 \mathrm{kPa}$

Fig. 13 Effects of cohesion and stiffness of encasement 


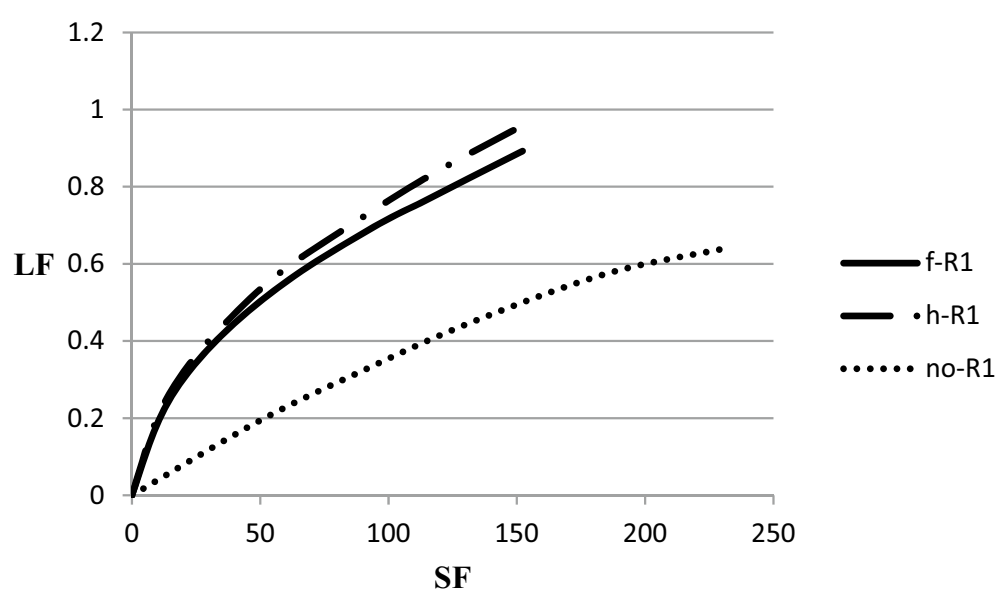

a Fine aggregate material $\left(\mathrm{R}_{1}\right)$

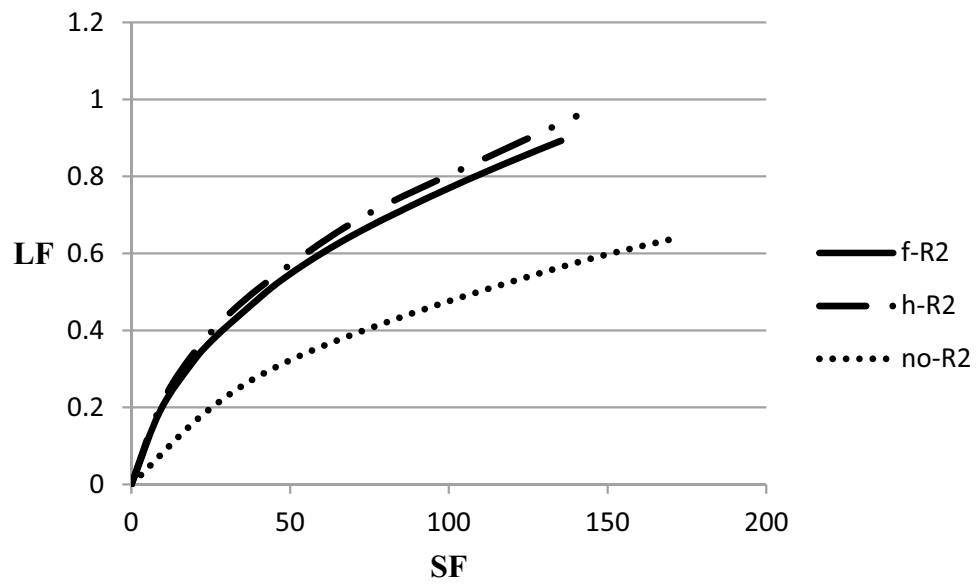

b Medium aggregate material $\left(\mathrm{R}_{2}\right)$

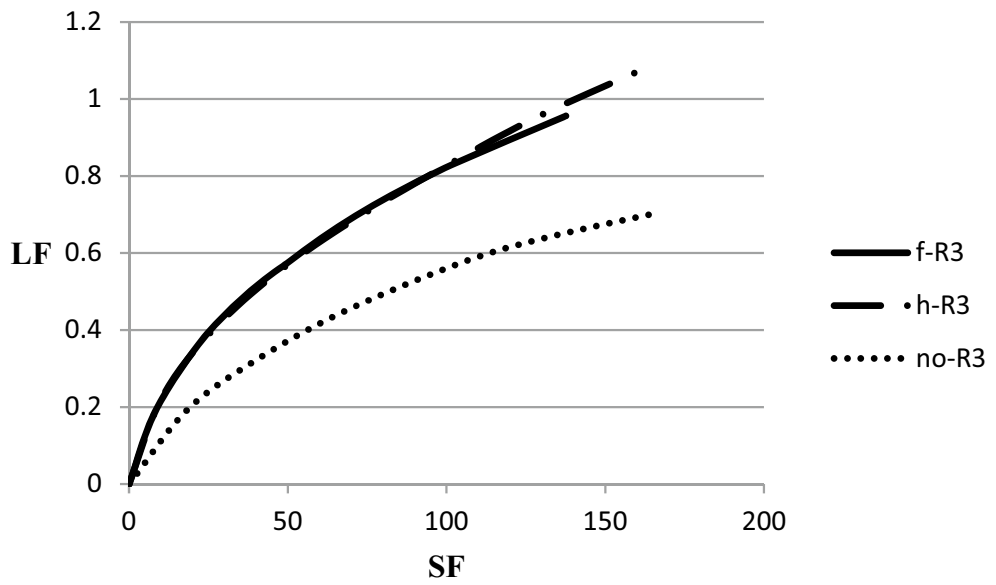

c Coarse aggregate materials $\left(\mathrm{R}_{3}\right)$

Fig. 14 Effects of length of encasement and type of aggregate 


\section{Conclusion}

A series of compression tests were conducted on model encased and uncased column embedded in cohesive and granular soils. The results of the testing program give some important insight into the performance of the encased stone columns. In addition to experimental investigations, numerical studies using commercial finite element computer code was carried out. It is observed that partially encased columns are superior to the fully encased ones. Use of different size of aggregate materials showed this parameter has considerable influence on bearing capacity of non-encased stone columns, but this effect is not evident for encased ones. In other words, for the smaller size of materials, encasing the stone columns makes more improvement than coarser materials. At stone columns formed with coarser aggregates, the radial strains reduced; hence the additional confining pressures reduced too. Compression tests results also showed encasing the stone columns in clay bed is more effective than in sand. Parametric studies were conducted to investigate the effect of soil cohesion and stiffness of encasement in clay bed. It was shown there is a threshold for stiffness of encasement beyond that, no significant increase in the bearing capacity is observed. The cohesion of the surrounding soil inversely affects the influence of encasement. It worth noting that the above findings are limited to the conditions and materials tested and further studies needed to investigate the effect of changing the encasement materials and conditions.

\section{Authors' contributions}

We confirm that the manuscript has been read and approved by all named authors and that there are no other persons who satisfied the criteria for authorship but are not listed. We further confirm that the order of authors listed in the manuscript has been approved by all of us. NH has supervised the project and conceived of the presented idea. NN conducted the experiments and performed the numerical analysis. AS and $\mathrm{NH}$ took the lead in writing the manuscript. All authors contributed to the final version of the manuscript. All authors read and approved the final manuscript.

\section{Competing interests}

The authors declare that they have no competing interests.

Received: 6 December 2018 Accepted: 30 March 2020

Published online: 18 April 2020

\section{References}

1. Ali K, Shahu JT, Sharma KG (2014) Model tests on single and groups of stone columns with different geosynthetic reinforcement arrangement. Geosynth Int. 21(2):103-118

2. Ambily AP, Gandhi SR (2007) Behavior of stone columns based on experimental and FEM analysis. J Geotech Geoenviron Eng ASCE. 133(4):405-415

3. ASTM D3080/D3080M-11, Standard test method for direct shear test of soils under consolidated drained conditions

4. ASTM D4595-09, Standard test method for tensile properties of geotextiles by wide-width strip method

5. Black JA, Sivakumar V, Madhav MR, Hamill GA (2007) Reinforced stone columns in weak deposits: laboratory model study. J Geotech Geoenviron Eng. 133(9):1154-1161

6. Castro J (2014) Numerical modelling of stone columns beneath a rigid footing. Comput Geotech 60:77-87

7. Dash SK, Bora MC (2013) Influence of geosynthetic encasement on the performance of stone columns floating in soft clay. Can Geotech J 50:754-765

8. Debnath P, Dey AK (2017) Bearing capacity of geogrid reinforced sand over encased stone columns in soft clay. Geotext Geomembr 45(6):653-664

9. Fattah M, Majeed Q (2012) Finite element analysis of geogrid encased stone columns. Geotech Geol Eng 30:713-726

10. Ghazavi M, Nazari Afshar J (2013) Bearing capacity of geosynthetic encased stone columns. Geotext Geomembr 38:26-36

11. Gniel J, Bouazza A (2009) Improvement of soft soils using geogrid encased stone columns. Geotext Geomembr 27(3):167-175

12. Gniel J, Bouazza A (2010) Construction of geogrid encased stone columns: a new proposal based on laboratory testing. Geotext Geomembr 27(3):167-175 
13. Greenwood DA (1970) Mechanical improvement of soils below ground surface. In: Proceedings of Ground Improvement Conference. Institute of Civil Engineering p 9-29

14. Hughes JMO, Withers NJ, Greenwood DA (1975) A field trial of the reinforcing effect of a stone column in soil. Geotechnique 25(1):31-44

15. Keykhosropur L, Soroush A, Imam R (2012) 3D numerical analyses of geosynthetic encased stone columns. Geotext Geomembr 35:61-68

16. McKelvey D, Sivakumar V, Bell A, Graham J (2004) Modeling vibrated stone columns in soft clay. J Geotechnical Eng 157(3):137-149

17. Mehrannia N, Kalantary F, Ganjian N (2018) Experimental study on soil improvement with stone columns and granular blankets. Cent South Univ. 25:866. https://doi.org/10.1007/s11771-018-3790-z

18. Miranda M, Da Costa A (2016) Laboratory analysis of encased stone columns. Laboratory analysis of encased stone columns. Geotext Geomembr 44:269-277

19. Murugesan S, Rajagopal K (2006) Geosynthetic-encased stone columns: numerical evaluation. Geotext Geomembr 24(6):349-358

20. Murugesan S, Rajagopal K (2007) Model tests on geosynthetic-encased stone columns'. Geosynthetics Int 14(6):346-354

21. Murugesan S, Rajagopal K (2010) Studies on the behavior of single and group of geosynthetic encased stone columns. J Geotech Geoenviron Eng. 136(1):129-139

22. Yoo C, Lee D (2012) Performance of geogrid-encased stone columns in soft ground: full-scale load tests. Geosynth Int. 19(6):480-490

23. Wood DM, Hu W, Nash FT (2000) Group effects in stone column foundations: model tests. Geotechnique 50(6):689-698

\section{Publisher's Note}

Springer Nature remains neutral with regard to jurisdictional claims in published maps and institutional affiliations.

\section{Submit your manuscript to a SpringerOpen ${ }^{\circ}$ journal and benefit from:}

- Convenient online submission

- Rigorous peer review

- Open access: articles freely available online

- High visibility within the field

Retaining the copyright to your article

Submit your next manuscript at $\gg$ springeropen.com 